\title{
Intraoperative Management of a Hybrid Extracorporeal Membrane Oxygenation Circuit for Lung Transplantation
}

\author{
Archer Martin ${ }^{1}$, Barry Harrison ${ }^{1}$, Ashley Fritz ${ }^{1}$, Kevin Landolfo ${ }^{2}$, Ian Makey ${ }^{1}$, Basar \\ Sareyyupoglu ${ }^{2}$, Thomas Brown ${ }^{3}$, James Johnson ${ }^{3}$, Si Pham ${ }^{4}$, and Mathew Thomas ${ }^{4}$ \\ ${ }^{1}$ Mayo Clinic \\ ${ }^{2}$ Mayo Clinic Florida \\ ${ }^{3}$ Mayo Clinic Hospital Jacksonville \\ ${ }^{4}$ Mayo Clinic's Campus in Florida
}

August 17, 2020

\begin{abstract}
The use of extracorporeal circulation (ECC) for intraoperative cardiopulmonary support during lung transplantation has been increasing in the recent years. Our group previously described a novel hybrid extracorporeal membrane oxygenation (ECMO) circuit for use in lung transplantation. Our novel technique for intraoperative management of this circuit during lung transplantation is described.

Perioperative management of lung transplantation has recently evolved with an increasing use of intraoperative extracorporeal circulation (ECC) reported in the literature. ${ }^{1}$ Intraoperative ECC for management of lung transplantation can be achieved with an extracorporeal membrane oxygenation (ECMO) circuit, cardiopulmonary bypass (CPB) circuit, or a hybrid ECMO-CPB circuit. $^{2}$ We previously described a novel design for an intraoperative hybrid ECMO circuit that is both cost-effective and facilitates conversion to $\mathrm{CPB}$ if necessary (Figure 1). ${ }^{2}$ Our novel technique for intraoperative management of the hybrid ECMO-CPB circuit, including considerations for monitoring and an organ-based management approach including cardiac, respiratory, and neurological systems is described.
\end{abstract}

\section{Technique}

\section{Monitoring Considerations}

Prior to surgery, the surgical and anesthesia teams formulate a plan regarding the surgical approach, cannulation sites, need for and type of ECC to be used. In the operating room, prior to induction of anesthesia, a variety of monitors are placed on the patient including pulse oximetry, electrocardiogram leads, non-invasive blood pressure monitoring, and a combination bilateral cerebral oximetry/anesthetic depth monitor (Masimo O3 ${ }^{\mathrm{TM}}$ Regional Oximetry with Sedline ${ }^{\mathrm{TM}}$ Brain Function Monitor, Masimo, Neuchatel, Switzerland). The timing of placement of the radial arterial line is at the discretion of the anesthesiologist, and may be placed prior to induction of anesthesia in the setting of severe ventricular dysfunction or when hemodynamic compromise is anticipated upon the application of positive pressure ventilation after endotracheal intubation. ${ }^{3}$ After induction of anesthesia and endotracheal intubation with a dual lumen endotracheal tube, we place a femoral arterial line, central venous catheter, pulmonary arterial catheter, end-tidal carbon dioxide $\left(\mathrm{ETCO}_{2}\right)$ monitor and transesophageal echocardiogram (TEE) probe. A TEE probe is placed in every lung transplant in order to guide ECMO cannula placement, monitor biventricular function, and assess the patency of pulmonary vasculature both prior to and following surgical anastomoses. ${ }^{4}$ After initiation of veno-arterial ECMO 
(VA-ECMO), we obtain a whole blood lactate, arterial blood gas (ABG), and activated clotting time (ACT) every 30 minutes. Additionally, we check a fibrinogen and prothrombin time/international normalized ratio (PT/INR) every 2 hours. In addition to these structured blood draws, we use an in-line device (Terumo CDI 550, Terumo Cardiovascular, Ann Arbor, MI, USA) to monitor real-time trends of $\mathrm{pH}$, partial pressures of oxygen and carbon dioxide $\left(\mathrm{PO}_{2}\right.$ and $\left.\mathrm{PCO}_{2}\right)$, potassium, oxygen delivery $\left(\mathrm{DO}_{2}\right)$, and hemoglobin within the hybrid ECMO-CPB circuit.

\section{Cardiac Considerations}

As described in our previous article ${ }^{2}$, we aim to divert the majority of calculated flow target cardiac output away from the pulmonary system into the VA-ECMO output, consistent with previously published reports. ${ }^{5}$ The ECC circuit reduces native cardiopulmonary blood flow to facilitate surgical exposure and dissection, and attenuates ischemic-reperfusion injury. ${ }^{5}$ Maintaining a balance between the ECMO flows and native cardiac output is a necessity to achieve appropriate systemic perfusion, avoidance of intra-cardiac clot formation, and provide controlled reperfusion of implanted donor grafts. Communication between the surgical and anesthesia teams is paramount. TEE, $\mathrm{ETCO}_{2}$, and the presence of pulsatility within the arterial and pulmonary arterial waveforms are used to determine the ideal circuit and native blood flow.

Surgical manipulations of the heart may cause abrupt changes in cardiac preload and contractility. Ongoing assessment of preload within the system is vital to avoid ECMO suction events ("chattering in the lines"). ${ }^{2}$ Due to the significant diversion of cardiac output to the hybrid ECMO circuit, the TEE is unable to accurately assess cardiac preload while on ECMO, yet remains useful as a direct monitor of cardiac contractility. We utilize $\mathrm{ETCO}_{2}$ as a semi-quantitative/qualitative monitor of system preload based on the principle of $\mathrm{ETCO}_{2}$ correlating with cardiac output. ${ }^{6,7}$ During implantation of the donor lung, mechanical ventilation is applied to the contralateral side via a double-lumen endotracheal tube. A value of $>20 \mathrm{~mm} \mathrm{Hg}$ as a goal value for our $\mathrm{ETCO}_{2}$ during hybrid ECMO was chosen based on trauma literature which notes that value as a threshold of adequate cardiac output during successful cardiopulmonary resuscitation. ${ }^{6}$ Pulsatility in both the pulmonary arterial and systemic arterial waveforms confirms biventricular output and provides a constant assessment of systemic afterload. The loss of pulsatility waveforms is associated with derangements of balance between the native and mechanical cardiac outputs, including decreased biventricular contractility, inadequate preload or inappropriately high ECMO target flows.

\section{Pulmonary Considerations}

Management of the pulmonary system during hybrid ECMO includes application of information obtained from cardiac monitors as well as evidence-based maneuvers to decrease the risk of developing primary graft dysfunction (PGD) during the perioperative period. Adequate $\mathrm{ETCO}_{2}$ and pulmonary arterial pulsatility are indicators of right ventricle cardiac output ensuring controlled perfusion of the newly implanted graft during hybrid ECMO. Post lung implantation, the pulmonary venous cuff is evaluated with pulse wave Doppler (PWD) via TEE in order to qualitatively detect the presence of cardiac output within the lung and to identify potential pulmonary vein obstruction. Mechanical ventilation of the lungs on ECMO is based on evidence from the literature, with the goal of minimizing injury to the implanted grafts being achieved using a lung protective approach with fraction of inspired oxygen $\left(\mathrm{FiO}_{2}\right)<40 \%$. ${ }^{1,8}$ We also administer inhaled anesthetic via both the hybrid ECMO circuit and the anesthesia machine, as the use of inhaled anesthetics has been shown to decrease formation of pulmonary edema and improve partial pressure of oxygen $/ \mathrm{FiO}_{2}$ ratios in animal lung transplantation models. ${ }^{1}$

\section{Neurological Considerations}

The use of a combination bilateral cerebral oximetry/anesthetic depth monitor during hybrid ECMO allows for monitoring of anesthetic depth and ensuring adequate cerebral oxygenation. Anesthetic depth must be monitored and titrated, due to the use of inhaled anesthetic in both the mechanical (hybrid ECMO) and native (lungs via the anesthesia machine) cardiac outputs to assure both adequate depth of anesthesia and to provide theoretical protection against the development of PGD. Hybrid ECMO cannulation can be either central or peripheral, and the use of cerebral oximetry monitoring provides information regarding 
both cerebral perfusion and oxygenation in hopes to avoid differential hypoxemia (north-south syndrome) associated with peripheral VA-ECMO. ${ }^{1}$

\section{Comments}

We previously described a hybrid ECMO-CPB circuit that provides lung transplantation teams the ability to provide ECC via either VA-ECMO or $\mathrm{CPB}^{2}$ While the goals for intraoperative management of ECMO include maintenance of systemic perfusion and controlled reperfusion of the newly implanted lungs, achieving the balance between native and mechanical cardiac outputs can be challenging. Despite these challenges, successful implementation of VA-ECMO is important as it can provide theoretical attenuation of the ischemic-reperfusion injury and improved perioperative outcomes. ${ }^{5}$ As summarized in Table 1 , the use of an organ system-based approach based on best evidence and anesthetic monitors that are multi-faceted yet complementary in design has enabled use of the hybrid ECMO circuit for intraoperative ECC since September 2017. Future concepts of investigation for intraoperative management of the hybrid circuit include the utility of goal-directed perfusion using $\mathrm{DO}_{2}$ and TEE-guided quantification of native cardiac output through the implanted grafts. Appropriately designed studies, both within our institution and in coordination with other centers, are needed to assess the efficacy of our approach for lung transplantation.

\section{Author contributions:}

AKM: Concept/design, drafting article, critical revision of article, Approval of article

BAH: Concept/design, drafting article, critical revision of article, Approval of article

AVF: Concept/design, drafting article, critical revision of article, Approval of article

KPL: Concept/design, drafting article, critical revision of article, Approval of article

IAM: Concept/design, drafting article, critical revision of article, Approval of article

BS: Concept/design, drafting article, critical revision of article, Approval of article

TEB: Concept/design, drafting article, critical revision of article, Approval of article

JLJ: Concept/design, drafting article, critical revision of article, Approval of article

SMP: Concept/design, drafting article, critical revision of article, Approval of article

MT: Concept/design, drafting article, critical revision of article, Approval of article

contributions:

\section{References}

1) Martin AK, Yalamuri SM, Wilkey BJ, Kolarczyk L, Fritz AV, Jayaraman A, Ramakrishna H. The Impact of Anesthetic Management on Perioperative Outcomes in Lung Transplantation. J Cardiothorac Vasc Anesth 34: 1669-1680, 2020.

2) Thomas M, Martin AK, Allen WL, Makey IA, Renew JR, Rodrigues ES, Mordecai MM, Brown TE, Foeks JJ, Johnson JL, Landolfo KL, Pham SM. Lung Transplantation Using a Hybrid Extracorporeal Membrane Oxygenation Circuit. ASAIO J 2020.

3) Martin AK, Fritz AV, Wilkey BJ. Anesthetic management of lung transplantation: impact of presenting disease. Curr Opin Anaesthesiol 33: 43-49, 2020.

4) Abrams BA, Melnyk V, Allen WL, Subramaniam K, Scott CD, Mitchell JD, Seres T, Martin AK. TEE for Lung Transplantation: A Case Series and Discussion of Vascular Complications. J Cardiothorac Vasc Anesth34: 733-740, 2020.

5) Hoetzenecker K, Schwarz S, Muckenhuber M, Benazzo A, Frommlet F, Schweiger T, Bata O, Jaksch P, Ahmadi N, Murakozy G, Prosch H, Hager H, Roth G, Lang G, Taghavi S, Klepetko W. Intraoperative 
extracorporeal membrane oxygenation and the possibility of postoperative prolongation improve survival in bilateral lung transplantation. J Thorac Cardiovasc Surg 155: 2193-2206 e2193, 2018.

6) Kodali BS, Urman RD. Capnography during cardiopulmonary resuscitation: Current evidence and future directions. J Emerg Trauma Shock 7: 332-340, 2014.

7) Macedo FI, Panos AL, Andreopoulos FM, Salerno TA, Pham SM. Lung perfusion and ventilation during implantation of left ventricular assist device as a strategy to avoid postoperative pulmonary complications and right ventricular failure. Interact Cardiovasc Thorac Surg 17: 764-766, 2013.

8) Diamond JM, Lee JC, Kawut SM, Shah RJ, Localio AR, Bellamy SL, Lederer DJ, Cantu E, Kohl BA, Lama VN, Bhorade SM, Crespo M, Demissie E, Sonett J, Wille K, Orens J, Shah AS, Weinacker A, Arcasoy S, Shah PD, Wilkes DS, Ware LB, Palmer SM, Christie JD. Clinical risk factors for primary graft dysfunction after lung transplantation. Am J Respir Crit Care Med 187: 527-534, 2013.

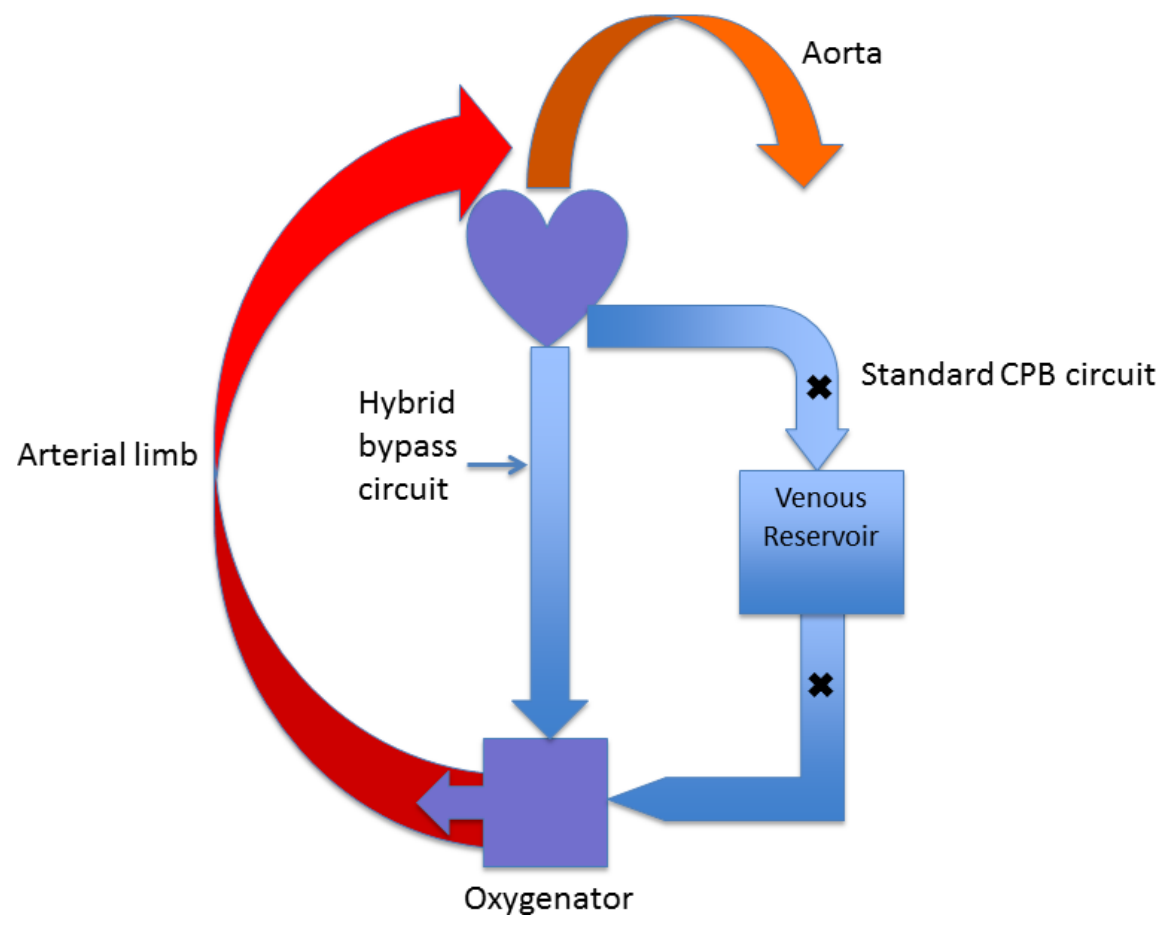

\section{Hosted file}

Table 1.docx available at https://authorea.com/users/330545/articles/475777-intraoperativemanagement-of-a-hybrid-extracorporeal-membrane-oxygenation-circuit-for-lungtransplantation 